\title{
ANALISIS PENGARUH KUALITAS PELAYANAN TERHADAP LOYALITAS PELANGGAN SITUS BOOKING ONLINE TRAVELOKA
}

\author{
Novian Ekawaty, Reminta Lumban Batu, Wanta \\ novianekawaty@gmail.com \\ reminta.lumban@fe.unsika.ac.id \\ wanta@ubpkarawang.ac.id
}

\begin{abstract}
ABSTRAK
Tujuan penelitian ini adalah untuk mengetahui bagaimana gambaran kualitas pelayanan, gambaran loyalitas pelanggan dan mengetahui pengaruh kualitas pelayanan terhadap loyalitas pelanggan. Populasi dalam penelitian ini adalah pengguna traveloka pada Google Play sebanyak 331.095 dan diambil sampel sebanyak 100 responden dengan menggunakan rumus slovin dengan tingkat error $10 \%$ melalui metode random sampling. Teknik analisis yang digunakan adalah analisis regresi linier sederhana dan uji asumsi klasik. Pengujian dilakukan dengan bantuan software SPSS versi 16. Hasil penelitian menunjukkan bahwa kualitas pelayanan secara simultan maupun parsial berpengaruh positif dan signifikan terhadap loyalitas pelanggan.
\end{abstract}

Keywords: Kualitas pelayanan, loyalitas pelanggan 


\section{PENDAHULUAN}

\subsection{Latar Belakang}

Perkembangan teknologi telekomunikasi dan komputer menyebabkan terjadinya perubahan kultur dan kebiasaan kita sehari-hari. Internet juga ternyata membawa perubahan yang besar bagi segala aspek terutama dalam perkembangan dunia bisnis dan pemasaran (Anggraeni and Madiawati 2016). Peningkatan jumlah pengguna internet memberikan dampak positif bagi perusahaan atau bisnis-bisnis yang menggunakan fasilitas internet. Peningkatan pengguna internet akan mendorong perusahaan untuk terus tumbuh, berkontribusi, dan melakukan inovasi dengan perkembangan ekonomi di Indonesia. Persaingan bisnis yang semakin kuat di era globalisasi membuat perusahaan dapat bersikap dan bertindak secara cepat dalam menghadapi persaingan bisnis yang bergerak sangat dinamis serta penuh dengan ketidakpastian (Ikka,(NURAINI 2017)

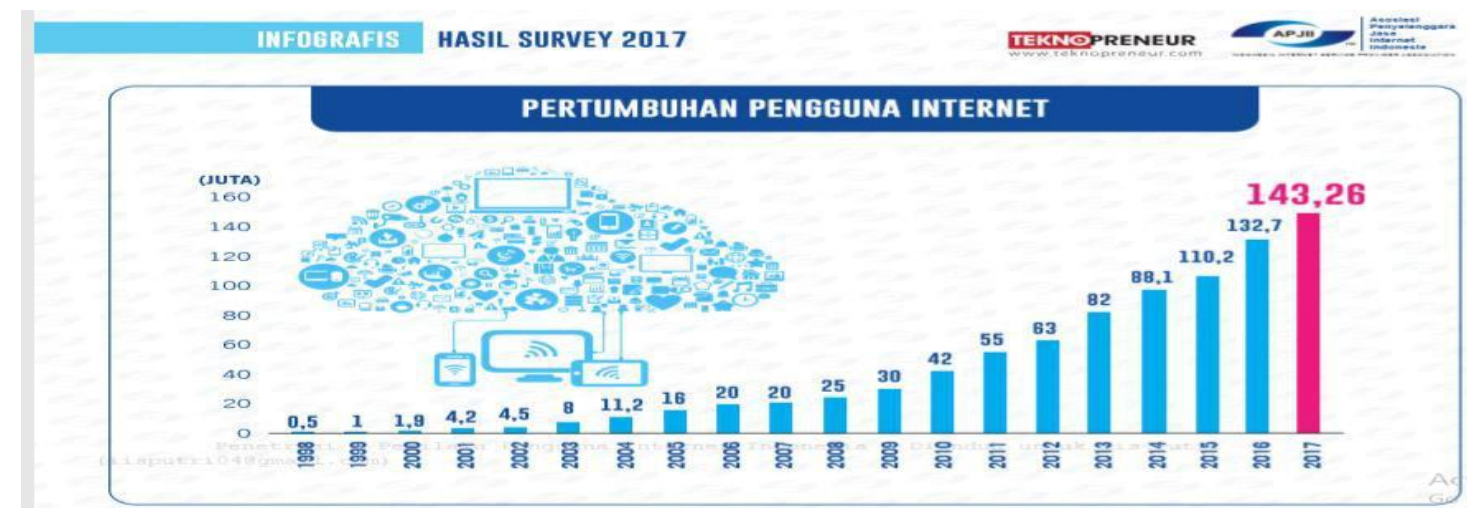

Sumber: (Asosiasi Penyelenggara Jasa Internet Indonesia n.d.)(diakses pada 17/10/2018 10.28)

GAMBAR 1.1

DATA PENGGUNA INTERNET TAHUN 1998-2017 
Masyarakat tidak hanya melakukan pembelian kebutuhan sehari-hari secara online, di era digital banyak masyarakat yang melakukan pembelian tiket pesawat, tiket kereta api, dan melakukan reservasi hotel secara online melalui situs-situs penjualan tiket pesawat dan hotel karena dinilai sangat mudah, cepat, dan praktis. Terdapat banyak perusahaan-perusahaan online yang menyediakan pembelian tiket pesawat dan booking hotel secara online dengan cepat dan praktis, diantaranya Traveloka, Mister Aladin, Tiket.com, NusaTrip, Pegi-pegi.com, Agoda, Ezy Travel, Halal Trip, dan GoIndonesia (id.Techinasia.com n.d.)diakses 16/10/2018 19:40).

Traveloka merupakan perusahaan yang bergerak dalam bidang pelayanan pemesanan tiket pesawat dan reservasi hotel secara online. Traveloka pertama kali didirikan oleh Ferry Unardi, Derianto Kusuma dan Albert yang pada awalnya hanya sebuah konsep untuk melihat dan membandingkan harga. Traveloka berubah menjadi situs reservasi yang kosentrasi dalam pemesanan tiket pesawat pada tahun 2013. Traveloka masuk ke bisnis reservasi kamar hotel Maret 2014 dan situs pemesanan hotel melalui Traveloka telah tersedia pada bulan Juli 2014.

Berbagai pelayanan yang diberikan Traveloka dimaksudkan untuk memberikan kualitas pelayanan yang baik terhadap konsumen sehingga diharapkan dapat memberikan kepuasan bagi konsumen yang berdampak pada minat pembelian ulang yang dilakukan oleh konsumen dan berujung kepada loyalitas konsumen. Loyalitas konsumen akan terbangun ketika terdapat kepercayaan konsumen terhadap perusahaan dan kualitas layanan yang memuaskan dari perusahaan terhadap konsumen. Berdasarkan data yang telah kami kumpulkan dapat diketahui bahwa presentase Traveloka menurun. Oleh karena itu, studi ini ingin mengetahui tentang pengaruh kualitas pelayanan terhadap loyalitas pelanggan maka judul penelitian yang kami ambil adalah “ Pengaruh Kualitas Pelayanan

\section{terhadap Loyalitas Pelanggan Traveloka"}




\section{METODE PENELITIAN}

\subsection{Metode Penelitian}

Metode penelitian pada dasarnya merupakan cara ilmiah untuk mendapatkan data dengan tujuan dan kegunaan tertentu. Cara ilmiah kegiatan penelitian itu didasarkan pada ciri-cir keilmuaan yaitu rasional, empiris, dan sistematis (sugiono,2013:2, Hendri,2016:27). Pada penelitian ini menggunakan metode penelitian deskriptif dan verifikatif.

Penelitian ini bertujuan untuk memperoleh gambaran mengenai variabel kualitas pelayanan sebagai variabel bebas dan loyalitas pelanggan sebagai variabel terikat. Secara verifikatif bertujuan untuk menguji hipotesis berdasarkan hasil pengolahan data yang secara statistik.

\subsection{Variabel Penelitian}

Variabel penelitian pada dasarnya adalah segala suesuatu yang berbentuk apa saja yang ditetapkan oleh peneliti untuk dipelajari sehingga diperoleh informasi tentang hal tersebut, kemudian ditarik kesimpulannya. Sugiyono (2012:28).

Dalam penelitian ini menggunakan dua variabel yaitu variabel bebas $(\mathrm{X})$ dan variabel terikat $(\mathrm{Y})$. variabel $\mathrm{X}$ adalah kualitas pelayanan merupakan variabel yang mempengaruhi variabel Y yaitu loyalitas pelanggan Traveloka.

\subsubsection{Definisi Operasional}

TABEL 3.1

DEFINISI OPERASIONAL VARIABEL

\begin{tabular}{|c|c|c|c|c|c|c|}
\hline Variabel & Konsep Variabel & Sub Variabel & Indikator & Pengukuran & Skala & $\begin{array}{l}\text { No } \\
\text { item }\end{array}$ \\
\hline $\begin{array}{l}\text { Kualitas } \\
\text { Layanan } \\
(\mathrm{X})\end{array}$ & $\begin{array}{c}\text { Kualitas Layanan } \\
\text { (service quality) } \\
\text { terdapat dua }\end{array}$ & $\begin{array}{l}\text { Reliability } \\
\text { (Kehandalan) }\end{array}$ & $\begin{array}{l}\text { 1.Pemesanan } \\
\text { tiket mudah } \\
\text { dilakukan }\end{array}$ & $\begin{array}{l}\text { 1. Tingkat } \\
\text { kemudahan }\end{array}$ & Interval & 1 \\
\hline \multirow{5}{*}{$\begin{array}{c}\text { Sumber: } \\
\text { Parasuraman, } \\
\text { et al., (1988) } \\
\text { dalam } \\
\text { Tjiptono, } \\
(2014)\end{array}$} & \multirow{5}{*}{$\begin{array}{c}\text { faktor utama yang } \\
\text { mempengaruhi } \\
\text { yakni, layanan } \\
\text { yang diharapkan } \\
\text { (expected service) } \\
\text { dan layanan yang } \\
\text { dipersepsikan } \\
\text { (perceived } \\
\text { service). Sumber : } \\
\text { Oliver dalam } \\
\text { Hurriyati } \\
\text { (2005:128),(Aber- } \\
\text { ian dan Ruzikna : } \\
\text { 2015) }\end{array}$} & & $\begin{array}{l}\text { 2. Kesesuaian } \\
\text { kinerja dengan } \\
\text { harapan }\end{array}$ & $\begin{array}{l}\text { 2. Tingkat } \\
\text { kesesuaian } \\
\text { kinerja dengan } \\
\text { harapan }\end{array}$ & Interval & 2 \\
\hline & & & $\begin{array}{l}\text { 3. penyelesaian } \\
\text { berbagai } \\
\text { masalah }\end{array}$ & $\begin{array}{l}\text { 3. Tingkat } \\
\text { penanganan } \\
\text { masalah }\end{array}$ & Interval & 3 \\
\hline & & \multirow[t]{3}{*}{$\begin{array}{l}\text { Responsiveness } \\
\text { (Ketanggapan) }\end{array}$} & $\begin{array}{l}\text { 1. Pelayanan } \\
\text { yang Ramah }\end{array}$ & $\begin{array}{l}\text { 1. Tingkat } \\
\text { keramahan } \\
\text { pelayanan }\end{array}$ & Interval & 4 \\
\hline & & & $\begin{array}{l}\text { 2. Penyelesaian } \\
\text { berbagai } \\
\text { kendala }\end{array}$ & $\begin{array}{l}\text { 2. Tingkat } \\
\text { penanganan } \\
\text { kendala }\end{array}$ & Interval & 5 \\
\hline & & & $\begin{array}{l}\text { 3. Penyampaian } \\
\text { complain } \\
\text { dengan mudah }\end{array}$ & $\begin{array}{l}\text { 3. Tingkat } \\
\text { kemudahan } \\
\text { penyampaian } \\
\text { complain }\end{array}$ & Interval & 6 \\
\hline
\end{tabular}




\begin{tabular}{|c|c|c|c|c|c|c|}
\hline & & \multirow[t]{3}{*}{$\begin{array}{l}\text { Assurance } \\
\text { (Jaminan dan } \\
\text { Kepastian) }\end{array}$} & $\begin{array}{l}\text { 1. Keakuratan } \\
\text { informasi }\end{array}$ & $\begin{array}{l}\text { 1. Tingkat } \\
\text { keakuratan } \\
\text { informasi }\end{array}$ & Interval & 7 \\
\hline & & & $\begin{array}{l}\text { 2.Pelayanan } \\
\text { yang sopan }\end{array}$ & $\begin{array}{l}\text { 2. Tingkat } \\
\text { pelayanan }\end{array}$ & Interval & 8 \\
\hline & & & $\begin{array}{l}\text { 3. Pelanggan } \\
\text { bisa dengan } \\
\text { aman dalam } \\
\text { transaksi }\end{array}$ & $\begin{array}{l}\text { 3. Tingkat } \\
\text { keamanan dalam } \\
\text { transaksi }\end{array}$ & Interval & 9 \\
\hline & & Sub Variabel & Indikator & Pengukuran & Skala & $\begin{array}{l}\text { No } \\
\text { item }\end{array}$ \\
\hline & & \multirow[t]{3}{*}{$\begin{array}{l}\text { Empathy } \\
\text { (Empati) }\end{array}$} & $\begin{array}{l}\text { 1. Pemahaman } \\
\text { kebutuhan } \\
\text { pelanggan }\end{array}$ & $\begin{array}{l}\text { 1. Tingkat } \\
\text { Pemahaman }\end{array}$ & Interval & 10 \\
\hline & & & $\begin{array}{l}\text { 2. pelayanan } \\
\text { tanpa } \\
\text { memandang } \\
\text { status pelanggan }\end{array}$ & $\begin{array}{l}\text { 2.Tingkat } \\
\text { Pelayanan }\end{array}$ & Interval & 11 \\
\hline & & & $\begin{array}{l}\text { 3. Kemampu-an } \\
\text { berkomuni-kasi } \\
\text { dengan baik }\end{array}$ & $\begin{array}{l}\text { 3. Tingkat } \\
\text { komunikasi }\end{array}$ & Interval & 12 \\
\hline & & \multirow[t]{3}{*}{ Tangibles } & $\begin{array}{l}\text { 1. Fasilitas yang } \\
\text { ada terawat } \\
\text { dengan baik }\end{array}$ & $\begin{array}{l}\text { 1. Tingkat } \\
\text { Perawatan } \\
\text { fasilitas }\end{array}$ & Interval & 13 \\
\hline & & & $\begin{array}{l}\text { 2.Keberagaman } \\
\text { produk }\end{array}$ & $\begin{array}{l}\text { 2. Tingkat } \\
\text { keberagaman } \\
\text { produk }\end{array}$ & Interval & 14 \\
\hline & & & $\begin{array}{l}\text { 3. Situs yang } \\
\text { memiliki desain } \\
\text { menarik }\end{array}$ & $\begin{array}{l}\text { 3. Tingkat } \\
\text { tampilan situs }\end{array}$ & Interval & 15 \\
\hline \multirow[t]{8}{*}{$\begin{array}{c}\text { LOYALITAS } \\
\text { PELANGGAN } \\
(\mathbf{Y})\end{array}$} & \multirow{8}{*}{$\begin{array}{l}\text { Loyalitas } \\
\text { Pelanggan adalah } \\
\text { komitmen } \\
\text { pelanggan } \\
\text { bertahan secara } \\
\text { mendalam untuk } \\
\text { berlangganan } \\
\text { kembali atau } \\
\text { melakukan } \\
\text { pembelian ulang } \\
\text { produk/ jasa yang } \\
\text { terpilih secara } \\
\text { konsisten dimasa } \\
\text { yang akan datang, } \\
\text { meskipun } \\
\text { pengaruh situasi } \\
\text { dan usaha-usaha } \\
\text { pemasaran } \\
\text { mempunyai } \\
\text { potensi untuk } \\
\text { menyebabkan } \\
\text { perubahan } \\
\text { perilaku } \\
\text { Sumber : Oliver } \\
\text { dalam Hurriyati } \\
\text { (2005:128),(Aber- } \\
\text { ian dan Ruzikna : } \\
\text { 2015) }\end{array}$} & \multirow[t]{3}{*}{$\begin{array}{l}\text { Say Positive } \\
\text { Thing }\end{array}$} & $\begin{array}{l}\text { 1. Pemberian } \\
\text { informasi } \\
\text { mengenai } \\
\text { perusahaan }\end{array}$ & $\begin{array}{l}\text { 1.Tingkat } \\
\text { pemberian } \\
\text { informasi }\end{array}$ & Interval & 16 \\
\hline & & & $\begin{array}{l}\text { 2. Ulasan cerita } \\
\text { dari pelanggan } \\
\text { kepada pihak } \\
\text { lain }\end{array}$ & $\begin{array}{l}\text { 2.Tingkat ulasan } \\
\text { cerita }\end{array}$ & Interval & 17 \\
\hline & & & $\begin{array}{l}\text { 3. Pemberian } \\
\text { informasi } \\
\text { mengenai } \\
\text { produk }\end{array}$ & $\begin{array}{l}\text { 3. Tingkat } \\
\text { pemberian } \\
\text { informasi }\end{array}$ & Interval & 18 \\
\hline & & \multirow[t]{3}{*}{$\begin{array}{l}\text { Recommend to } \\
\text { friends }\end{array}$} & $\begin{array}{l}\text { 1.Rekomendasi } \\
\text { kepada orang } \\
\text { lain mengenai } \\
\text { layanan }\end{array}$ & $\begin{array}{l}\text { 1.Tingkat } \\
\text { perekomendasian }\end{array}$ & Interval & 19 \\
\hline & & & $\begin{array}{l}\text { 2. Ajakan orang } \\
\text { lain untuk } \\
\text { menggunakan } \\
\text { layanan }\end{array}$ & $\begin{array}{l}\text { 2. Tingkat ajakan } \\
\text { orang lain }\end{array}$ & Interval & 20 \\
\hline & & & $\begin{array}{l}\text { 3. Penciptaan } \\
\text { pengalaman } \\
\text { positif }\end{array}$ & $\begin{array}{l}\text { 3. Tingkat } \\
\text { penciptaan } \\
\text { pengalaman }\end{array}$ & Interval & 21 \\
\hline & & \multirow[t]{2}{*}{$\begin{array}{l}\text { Continue } \\
\text { purchasing }\end{array}$} & $\begin{array}{l}\text { 1.Ketepatan } \\
\text { waktu dalam } \\
\text { membayar } \\
\text { tagihan }\end{array}$ & $\begin{array}{l}\text { 1.Tingkat } \\
\text { ketepatan waktu }\end{array}$ & Interval & 22 \\
\hline & & & $\begin{array}{l}\text { 2. Komitmen } \\
\text { untuk selalu } \\
\text { menggunakan } \\
\text { layanan }\end{array}$ & $\begin{array}{l}\text { 2. Tingkat } \\
\text { komitmen }\end{array}$ & Interval & 23 \\
\hline
\end{tabular}




\subsubsection{Definisi Konseptual}

Definisi konseptual kualitas pelayanan adalah suatu proses yang diberikan perusahaan untuk konsumen dalam rangka memberikan pelayanan yang baik, sebagaimana dengan dimensi-dimensi yang ada antara lain Realibility, Ressponsiveness, Asurance, Empathy, dan Tangibles. Sedangkan, definisi konseptual loyalitas adalah suatu sikap yang lebih mengacu pada wujud perilaku pada pengambilan keputusan konsumen untuk melakukan pembelian secara berulang terhadap barang dan jasa yang ditawarkan oleh perusahaan serta merekomendasikan kepada orang lain, dengan dimensi kualitas pelayanan.

\subsection{Teknik Pengumpulan Data}

\subsubsection{Populasi}

"Populasi adalah kelompok elemen yang lengkap, yang biasanya berupa orang, objek, transaksi, atau kejadian dimana kita tertarik untuk mempelajari atau menjadi objek penilitian.” (Mudrajad Kuncoro, “Metode Riset Untuk Bisnis dan Ekonomi”, Edisi 4, Penerbit Erlangga, Jakarta, 2013, Hal 110

Populasi dari penelitian ini adalah pengguna Traveloka yang berjumlah 331.095 pengguna. Jumlah tersebut diperoleh dari penilaian aplikasi Traveloka pada Google playstore.

\subsubsection{Sampel}

Menurut Sugiyono (2016:81) mendefinisikan sampel adalah sebagai berikut: "Sampetadalah bagian dari jumlah dan karakteristik yang dimiliki oleh populasi tersebut.

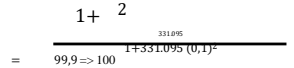

Jadi, anggota populasi yang diambil sebagai sampel adalah sebanyak 100 orang responden.

\subsection{Jenis Data dan Sumber Data}

1. Data Primer 
Data primer adalah data yang didapat dari hasil observasi secara keseluruhan, yaitu dengan cara menyebarkan kuisioner kepada seluruh responden yang dianggap sebagai data-data sebenarnya.

2. Data Sekunder

Yaitu dengan cara mencatat data-data yang telah diterbitkan oleh perusahaan dan juga melalui majalah-majalah dan website analis dalam hal ini adalah data pengguna internet, data pengunjung website, data top brand awards, data ranking perusahaan Traveloka.

\subsubsection{Sumber Data}

\section{Data Internal}

Data internal adalah data yang menggambarkan situasi dan kondisi pada suatu organisasi secara internal. Dimana data yang digunakan mencangkup data pengguna internet, data pengunjung website, data top brand awards, data ranking Traveloka.

\section{Data Eksternal}

Data Eksternal adalah data yang menggambarkan situasi serta kondisi yang ada diluar organisasi. Data eksternal diisi mencangkup pada kuisioner yang disebarkan kepada responden mewakili pendapat dari populasi yang ada.

\subsubsection{Teknik Pengumpulan Data}

Metode yang dilakukan dalam proses pengumpulan data dalam penelitian ini dengan cara:

1. Studi Kepustakaan, yaitu dengan cara mempelajari buku-buku sebagai landasan teori untuk memudahkan dalam mengimplementasikan sehingga memudahkan dalam menyusun penelitian.

2. Kuisioner, yaitu dengan cara membuat pertanyaan yang berkaitan dengan variabel dan cukup sederhana serta dikemas dalam bentuk angket/kuisioner yang berbasis internet.

\subsubsection{Teknik Skala}

Dalam pengukuran variabel terlebih dahulu menentukan skala pengukuran variabel. Skala pegukuran merupakan kesepakatan yang digunakan sebagai acuan untuk menentukan panjang pendeknya interval yang ada dalam alat ukur, sehingga alat ukur tersebut bila digunakan dalam pengukuran akan menghasilkan data kuantitatif Sugiyono (2013;46),(Siwalima2018) 


\subsection{Metode Analisi Data}

\subsubsection{Pengujian Validitas}

Validitas menunjukan sejauh mana skor/nilai ukuran yang diperoleh benar-benar menyatakan hasil pengukura/pengamatan. Validitas pada umumnya dipersalahkan berkaitan dengan hasil pengukuran psikologis atau non fisik. Berkaitan dengan karakteristik psikologis, hasil pengukuran yang diperoleh sebenarnya diharapkan dengan menggambarkan atau memberikan skor/nilai suatu karakteristik lain yang menjadi perhatian utama. Dengan uji coba instrument pada sampel dari populasi yang diambil 30 ,jumlah anggota sampel yang digunakan setelah itu ditabulasikan.

\subsubsection{Analisis Deskriptif}

Menurut Sugiyono (2012 : 206) stastistik deskriptif yaitu : "Statistik yang digunakan untuk menganalisis data dengan cara mendeskripsikan atau menggambarkan data yang telah terkumpul sebagaimana adanya tanpa bermaksud membuat kesimpulan yang berlaku untuk umum atau generalisasi." Hasil dari pengujian ini diharapkan mampu mengestimasi validitas dan realibitas data yang akan digunakan dalam uji statistik setiap hipotesis penelitian. Statistik deskriptif ini meliputi jumlah sampel $(\mathrm{N})$, rata-rata sampel (mean), nilai maksimum, nilai minimum, dan standar deviasi yang digunakan sebagai langkah awal analisis data.

\subsubsection{Pengujian Normalitas}

Uji Normalitas bertujuan untuk menguji apakah dalam model regresi, variabel terikat dan variabel bebas keduanya mempunyai distribusi normal. Model regresi yang baik adalah memiliki distribusi data normal/ mendekati normal. Cara mengetahui normalitas adalah dengan melihat normal probability plot yang membandingkan distribusi kumulatif dan distribusi normal.

Distribusi normal akan membentuk suatu garis lurus diagonal dan plotting data akan dibandingkan dengan garis diagonal. Jika distribusi data normal, maka garis yang memberikan data sesungguhnya akan mengikuti garis diagonalnya. Persyaratan dari uji normalitas adalah jika data menyebar disekitar garis diagonal dan mengikuti garis diagonal, jika tidak mengikuti garis diagonal maka model regresi tidak memenuhi asumsi normalitas. 
HASIL PENELITIAN DAN PEMBAHASAN

\section{Profil Responden}

\section{TABEL 4.1 \\ RESPONDEN BERDASARKAN JENIS KELAMIN}

\begin{tabular}{llc}
\hline Jenis Kelamin & Frekuensi & Persentase (\%) \\
\hline Laki-laki & 40 & $39,60 \%$ \\
\hline Perempuan & 61 & $60,40 \%$ \\
\hline
\end{tabular}

Sumber: Pengolahan Data 2018

Berdasarkan tabel 4.1 menunjukkan bahwa sebagian besar responden pada penelitian ini adalah perempuan dengan frekuensi sebanyak 61 responden dari total 101 responden.

\subsubsection{Profil Responden Berdasarkan Pekerjaan}

TABEL 4.2

\section{RESPONDEN BERDASARKAN PEKERJAAN}

\begin{tabular}{lcc}
\hline Pekerjaan & Frekuensi & Persentase (\%) \\
\hline Pelajar & 3 & $3,0 \%$ \\
\hline Mahasiswa & 75 & $74,30 \%$ \\
\hline PNS & 2 & $2,00 \%$ \\
\hline Karyawan Swasta & 13 & $12,90 \%$ \\
\hline Wiraswasta & 8 & $7,90 \%$
\end{tabular}

Sumber: Pengolahan Data 2018

Berdasarkan tabel 4.2 menunjukkan bahwa sebagian besar responden pada penelitian ini adalah mahasiswa dengan frekuensi sebanyak 75 responden dari total 101 responden.

\subsubsection{Profil Responden Berdasarkan Usia}

\section{TABEL 4.3}

RESPONDEN BERDASARKAN USIA

\begin{tabular}{lcc}
\hline Usia & Frekuensi & Persentase $(\%)$ \\
\hline$<17$ tahun & 3 & $3 \%$ \\
\hline $18-30$ tahun & 88 & $87,1 \%$ \\
\hline $31-40$ tahun & 6 & $5,90 \%$ \\
\hline $41-50$ tahun & 2 & $2,00 \%$ \\
\hline$>51$ tahun & 2 & $2,00 \%$ \\
\hline
\end{tabular}

Sumber: Pengolahan Data 2018

Berdasarkan tabel 4.3 menunjukkan bahwa sebagian besar responden pada penelitian ini berusia antara 18 sampai 30 tahun dengan frekuensi sebanyak 88 responden dari total 101 responden. 


\subsubsection{Profil Responden Berdasarkan Uang Saku}

TABEL 4.4

\section{RESPONDEN BERDASARKAN UANG SAKU}

\begin{tabular}{lll}
\hline Uang Saku Bulanan & Frekuensi & Persentase (\%) \\
\hline < Rp. 1.000.000 & 45 & $44,6 \%$ \\
\hline Rp. 1.000.001- Rp. 2.000.000 & 29 & $28,70 \%$ \\
\hline Rp. 2.000.001- Rp. 3.000.000 & 9 & $8,90 \%$ \\
\hline Rp. 3.000.001 - Rp. 4.000 .000 & 2 & $2,00 \%$ \\
\hline > Rp. 4.000 .000 & 16 & $15,80 \%$ \\
\hline
\end{tabular}

Sumber: Pengolahan Data 2018

Berdasarkan tabel 4.4 menunjukkan bahwa sebagian besar responden pada penelitian ini memiliki uang saku bulanan sebesar kurang dari Rp.1.000.000 dengan frekuensi sebanyak 45 responden dari total 101 responden.

\subsection{Analisis Deskriptif}

Gambaran Dimensi Say Positive Thing (Berkata Positif) bertujuan untuk memperoleh jawaban mengenai sejauh mana berkata positif dipertimbangkan oleh responden dan mampu mempengaruhi loyalitas pengguna Traveloka.

\subsubsection{Gambaran Dimensi Rekomendasi Kepada Teman}

Gambaran Dimensi Recommend To Friends (Rekomendasi Kepada Teman) bertujuan untuk memperoleh jawaban mengenai sejauh mana Rekomendasi Kepada Teman dipertimbangkan oleh responden dan mampu mempengaruhi loyalitas pengguna Traveloka.

TABEL 4.5

\section{DIMENSI RECOMMEND TO FRIEND (REKOMENDASI KEPADA TEMAN)}

\begin{tabular}{|c|c|c|c|c|c|c|c|c|}
\hline \multirow[t]{2}{*}{ No } & \multirow{2}{*}{\multicolumn{2}{|c|}{ Pernyataan }} & 1 & 2 & 3 & 4 & 5 & Jumlah \\
\hline & & & $\begin{array}{l}\text { Sangat } \\
\text { Tidak } \\
\text { Mereko } \\
\text { mendasik } \\
\text { an }\end{array}$ & $\begin{array}{l}\text { Tidak } \\
\text { Mereko } \\
\text { mendasik } \\
\text { an }\end{array}$ & $\begin{array}{l}\text { Cukup } \\
\text { Merekome } \\
\text { ndasikan }\end{array}$ & $\begin{array}{l}\text { Mereko } \\
\text { mendasik } \\
\text { an }\end{array}$ & $\begin{array}{l}\text { Sangat } \\
\text { Merekome } \\
\text { ndasikan }\end{array}$ & \\
\hline \multirow[t]{3}{*}{19} & \multirow{2}{*}{$\begin{array}{l}\text { Saya } \\
\text { merekomendasik }\end{array}$} & $\mathrm{F}$ & 1 & 4 & 42 & 43 & 11 & 101 \\
\hline & & Skor & 1 & 8 & 126 & 172 & 55 & 362 \\
\hline & $\begin{array}{l}\text { Traveloka } \\
\text { kepada orang } \\
\text { lain }\end{array}$ & $\%$ & $1 \%$ & $4 \%$ & $42 \%$ & $43 \%$ & $11 \%$ & $100 \%$ \\
\hline 20 & & & 1 & 2 & 3 & 4 & 5 & \\
\hline
\end{tabular}




\begin{tabular}{|c|c|c|c|c|c|c|c|}
\hline \multirow{4}{*}{$\begin{array}{l}\text { saya mampu } \\
\text { membuat orang } \\
\text { lain } \\
\text { menggunakan } \\
\text { situs Traveloka }\end{array}$} & & $\begin{array}{l}\text { Sangat } \\
\text { Tidak } \\
\text { Mengaja } \\
\text { k }\end{array}$ & $\begin{array}{l}\text { Tidak } \\
\text { Mengaja } \\
\text { k }\end{array}$ & $\begin{array}{l}\text { Cukup } \\
\text { Mengajak }\end{array}$ & $\begin{array}{l}\text { Mengaja } \\
\mathrm{k}\end{array}$ & $\begin{array}{l}\text { Sangat } \\
\text { Mengajak }\end{array}$ & \\
\hline & $\mathrm{F}$ & 0 & 6 & 51 & 31 & 13 & 101 \\
\hline & Skor & 0 & 12 & 153 & 124 & 65 & 354 \\
\hline & $\%$ & $0 \%$ & $6 \%$ & $50 \%$ & $31 \%$ & $13 \%$ & $100 \%$ \\
\hline \multirow{5}{*}{$\begin{array}{l}\text { 21Pengalaman } \\
\text { yang baik } \\
\text { membuat saya } \\
\text { mudah dalam } \\
\text { merekomendasik } \\
\text { an kepada orang } \\
\text { lain }\end{array}$} & & 1 & 2 & 3 & 4 & 5 & \\
\hline & & $\begin{array}{l}\text { Sangat } \\
\text { Tidak } \\
\text { Mudah }\end{array}$ & $\begin{array}{l}\text { Tidak } \\
\text { Mudah }\end{array}$ & $\begin{array}{l}\text { Cukup } \\
\text { Mudah }\end{array}$ & Mudah & $\begin{array}{l}\text { Sangat } \\
\text { Mudah }\end{array}$ & \\
\hline & $\mathrm{F}$ & 0 & 1 & 41 & 40 & 19 & 101 \\
\hline & skor & 0 & 2 & 123 & 160 & 95 & 380 \\
\hline & $\%$ & $0 \%$ & $1 \%$ & $41 \%$ & $40 \%$ & $19 \%$ & $100 \%$ \\
\hline Total & $\%$ & $0 \%$ & $4 \%$ & $44 \%$ & $38 \%$ & $14 \%$ & $100 \%$ \\
\hline
\end{tabular}

Sumber: Pengolahan Data 2018

Berdasarkan Tabel 4.12 menginformasikan pernyataan mana yang menurut responden sangat dipertimbangkan sampai pada pernyataan yang sangat tidak dipertimbangkan oleh responden. Diketahui persentase terdapat pada pernyataan "saya mampu membuat orang lain menggunakan situs Traveloka" yaitu sebesar 50\% setengah dari keseluruhan responden merasa cukup mampu membuat orang lain menggunakan situs Traveloka.

\subsubsection{Gambaran Dimensi Continue Purchasing (Pembelian Ulang)}

Gambaran Dimensi Continue Purchasing (Pembelian Ulang) bertujuan untuk memperoleh jawaban mengenai sejauh mana Pembelian Ulang dipertimbangkan oleh responden dan mampu mempengaruhi loyalitas pengguna Traveloka.

TABEL 4.6

DIMENSI CONTINUE PURCHASING (PEMBELIAN ULANG)

\begin{tabular}{llllllll}
\hline No & Pernyataan & $\mathbf{1}$ & $\mathbf{2}$ & $\mathbf{3}$ & $\mathbf{4}$ & $\mathbf{5}$ & Jumlah \\
\cline { 3 - 7 } & & $\begin{array}{l}\text { Sangat } \\
\text { Terlam } \\
\text { bat }\end{array}$ & $\begin{array}{l}\text { Terlam } \\
\text { bat }\end{array}$ & $\begin{array}{l}\text { Cukup } \\
\text { Tepat }\end{array}$ & Tepat & $\begin{array}{l}\text { Sangat } \\
\text { Tepat }\end{array}$ & \\
\hline $\mathbf{2 2}$ & $\begin{array}{l}\text { Saya tepat F } \\
\text { waktu dalam }\end{array}$ & 0 & 1 & 32 & 34 & 34 & 101 \\
\cline { 3 - 7 } & $\begin{array}{l}\text { melakukan } \\
\text { pembayaran }\end{array}$ & 0 & 2 & 96 & 136 & 170 & 404 \\
\hline $\mathbf{2 3}$ & & $\mathbf{1}$ & $\mathbf{2}$ & $\mathbf{3}$ & $\mathbf{4}$ & $\mathbf{5}$ & \\
\hline
\end{tabular}




\begin{tabular}{|c|c|c|c|c|c|c|c|c|}
\hline & \multirow{4}{*}{$\begin{array}{l}\text { Saya sering } \\
\text { melakukan } \\
\text { pembelian } \\
\text { ulang tiket } \\
\text { perjalanan }\end{array}$} & & $\begin{array}{l}\text { Sangat } \\
\text { Jarang }\end{array}$ & Jarang & $\begin{array}{l}\text { Cukup } \\
\text { Sering }\end{array}$ & Sering & $\begin{array}{l}\text { Sangat } \\
\text { Sering }\end{array}$ & \\
\hline & & $\mathrm{F}$ & 1 & 25 & 25 & 25 & 25 & 101 \\
\hline & & Skor & 1 & 50 & 75 & 100 & 125 & 351 \\
\hline & & $\%$ & $1 \%$ & $25 \%$ & $25 \%$ & $25 \%$ & $25 \%$ & $100 \%$ \\
\hline 24 & Saya sering & & 1 & 2 & 3 & 4 & 5 & \\
\hline & $\begin{array}{l}\text { melakukan } \\
\text { pembelian }\end{array}$ & & $\begin{array}{l}\text { Sangat } \\
\text { Jarang }\end{array}$ & Jarang & $\begin{array}{l}\text { Cukup } \\
\text { Sering }\end{array}$ & Sering & $\begin{array}{l}\text { Sangat } \\
\text { Sering }\end{array}$ & \\
\hline & $\begin{array}{l}\text { ulang } \\
\text { nerlenokanan }\end{array}$ & $\mathrm{F}$ & 1 & 28 & 30 & 18 & 24 & 101 \\
\hline & akomodasi & skor & 1 & 56 & 90 & 72 & 120 & 339 \\
\hline & & $\%$ & $1 \%$ & $28 \%$ & $30 \%$ & $18 \%$ & $24 \%$ & $100 \%$ \\
\hline & Total & $\%$ & $1 \%$ & $18 \%$ & $29 \%$ & $25 \%$ & $27 \%$ & $100 \%$ \\
\hline
\end{tabular}

Sumber: Pengolahan Data 2018

Berdasarkan Tabel 4.13 menginformasikan pernyataan mana yang menurut responden sangat dipertimbangkan sampai pada pernyataan yang sangat tidak dipertimbangkan oleh responden. Diketahui persentase terdapat pada pernyataan "Saya tepat waktu dalam melakukan pembayaran" yaitu sebesar 32\% lebih dari sepertiga responden merasa cukup mampu melakukan pembayaran tepat waktu.

\subsubsection{Rekapitulasi Variabel Y (Loyalitas Pelanggan)}

Secara keseluruhan variabel Loyalitas Pelanggan yang terdiri dari berkata positif, rekomendasi kepada teman, dan pembelian ulang dapat diketahui kedudukannya berdasarkan skor yang didapat dari rekapitulasi data, dimana nilai-nilai tersebut dibandingkan dengan kriteria skor standar yang didapatkan melalui perhitungan skor ideal (kriterium) dengan skor terkecil, sehingga melalui skor standar tersebut dapat diketahui daerah kontinum yang menunjukan wilayah ideal dari variabel, hal tersebut dapat dicari dengan rumus menurut Sugiyono (2010:135), langkah pertama menyusun rekapitulasi variable Loyalitas Pelanggan.

TABEL 4.7

\section{REKAPITULASI SKOR PENILAIAN GAMBARAN LOYALITAS PELANGGAN}

\begin{tabular}{|c|c|c|c|c|c|c|}
\hline No & Dimensi & & Skor Total & Rata-rata Skor & Skor Ideal & $\%$ \\
\hline 1 & $\begin{array}{l}\text { Say Positive Thing } \\
\text { Positif) }\end{array}$ & (Berkata & 1083 & 361 & 500 & $33,1 \%$ \\
\hline
\end{tabular}




\begin{tabular}{|c|c|c|c|c|c|}
\hline 2 & $\begin{array}{l}\text { Recommend To Friends } \\
\text { (Rekomendasi Kepada Teman) }\end{array}$ & 1096 & 365 & 500 & $33,48 \%$ \\
\hline 3 & $\begin{array}{l}\text { Continue Purchasing (Pembelian } \\
\text { Ulang) }\end{array}$ & 1094 & 364 & 500 & $33,42 \%$ \\
\hline & tas Pelanggan & 3273 & 1090 & & $100 \%$ \\
\hline
\end{tabular}

Sumber : Hasil Pengolahan Data, 2018

Berdasarkan tabel 4.14 menjelaskan mengenai rekapitulasi skor dari dimensidimiensi yang akan mempengaruhi loyalitas pelanggan. Dimensi yang memiliki skor rata rata tertinggi adalah dimensi Recommend To Friends (Rekomendasi Kepada Teman) sebesar 365 dengan presentase 33,48\%. Rekapitulasi gambaran kualitas pelayanan dapat dilihat dalam tinjauan kontinum secara keseluruhan melalui proses perhitungan berikut:

\subsection{Analisis Verifikatif}

Analisis regresi digunakan untuk mempelajari pengaruh variabel bebas (variabel prediktor) terhadap variabel terikat. Secara umum rumus persamaan regresi linier sederhana adalah $\mathrm{Y}=\mathrm{a}+\mathrm{bX}$ Perhitungan statistik dalam analisis regresi linear sederhana yang digunakan dalam penelitian ini menggunakan aplikasi spss 16. Ringkasan hasil pengolahan data dengan menggunakan program SPSS tersebut adalah sebagai berikut :

\section{TABEL 4.8}

\section{HASIL UJI REGRESI LINIER SEDERHANA}

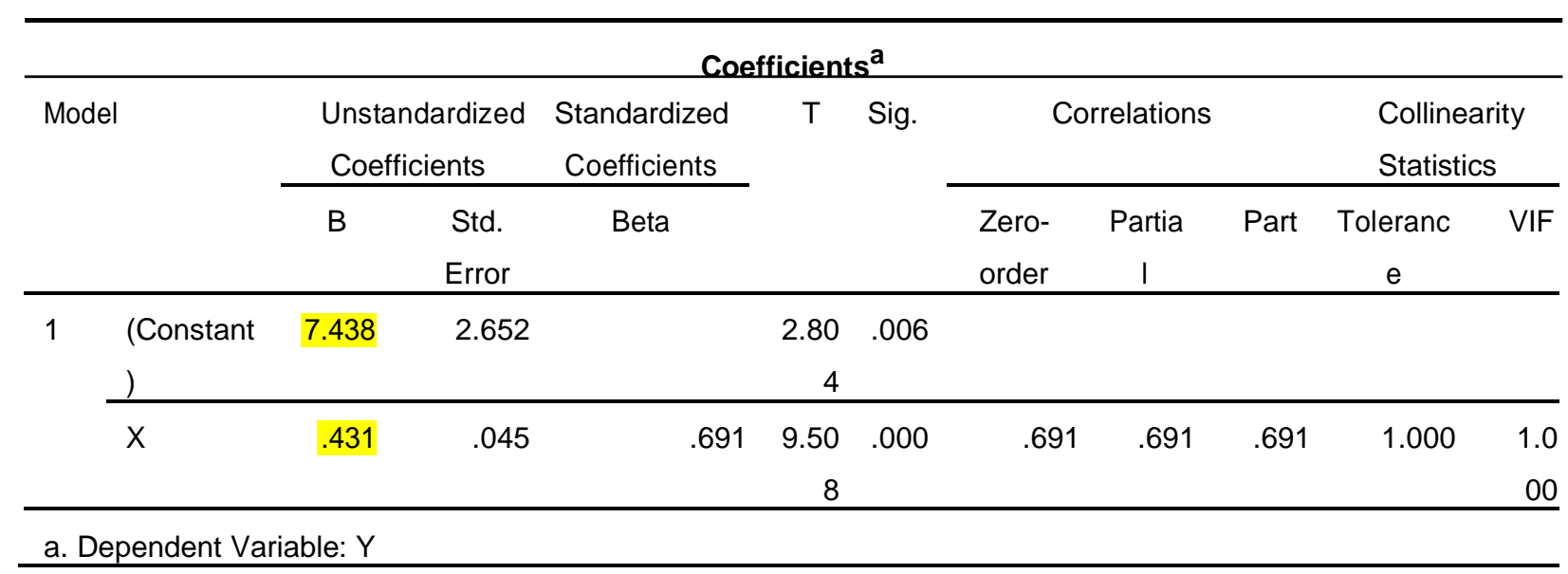

Sumber: Data primer diolah dengan SPSS 16.0

\subsection{Pembahasan}

Penelitian ini bertujuan untuk mengetahui: (1) gambaran variabel kualitas pelayanan pada situs booking online Traveloka, (2) gambaran variabel loyalitas pelanggan pada situs 
booking online Traveloka, (3) pengaruh kualitas pelayanan terhadap loyalitas pelanggan pada situs booking online Traveloka. Pembahasan masing-masing tujuan disajikan sebagai berikut:

\subsubsection{Pengaruh Kualitas Pelayanan terhadap Loyalitas Pelanggan}

Hasil statistik uji t untuk variabel kualitas pelayanan diperoleh nilai t hitung sebesar 9,508 dengan tingkat signifikansi 0,000, karena signifikansi lebih kecil dari 0,05 $(0,000<0,05)$, dan koefisien regresi mempunyai nilai positif sebesar 0,431 maka penelitian ini berhasil membuktikan bahwa "Kualitas pelayanan berpengaruh positif dan signifikan terhadap kepuasan pelanggan”. Hasil tersebut sesuai dengan hipotesis awal pada penelitian ini..

\section{KESIMPULAN DAN SARAN}

Berdasarkan hasil penelitian yang telah dilakukan menggunakan analisis deskriptif dan verifikatif maka berdasarkan penelitian tersebut dapat diambil kesimpulan sebagai berikut:

1. Gambaran variabel kualitas pelayanan diukur melalui dimensi Reliability (Kehandalan), Responsivness (Daya Tanggap), Assurance (Jaminan), Emphaty (Empati), Tangible (Bukti Fisik). Rata-rata skor tertinggi terdapat pada dimensi Assurance (Jaminan) dengan nilai rata-rata skor sebesar 960.

2. Gambaran variabel loyalitas pelanggan diukur melalui dimensi Say Positive Thing (Berkata Positif), Recommend To Friends (Rekomendasi Kepada Teman), Continue Purchasing (Pembelian Ulang) . Rata-rata skor tertinggi terdapat pada dimensi Recommend To Friends (Rekomendasi Kepada Teman) dengan nilai rata-rata skor sebesar 365

3. Terdapat pengaruh positif dan signifikan. Hasil ini menunjukkan bahwa penilaian yang baik mengenai pelayanan yang sesuai dengan tingkat baik atau tidaknya kualitas pelayanan yang diberikan mendorong pelanggan untuk setia terhadap jasa tersebut 


\subsection{Saran}

Berdasarkan hasil penelitian diketahui bahwa persepsi pelanggan pengguna jasa Traveloka variabel kualitas pelayanan dengan indikator responsiveness daya tanggap petugas mendapatkan rata-rata skor terendah yakni 380. Oleh karena itu, dalam memberikan pelayanan mengenai kemampuan customer service dalam membantu pelanggan menyelesaikan masalah lebih ditingkatkan lagi, agar pelanggan tidak merasa khawatir dan dapat meningkatkan kepercayaan pelanggan terhadap Traveloka . Walaupun untuk pelayanan yang lain seperti Jaminan (assurance), bukti fisik (tangible), kehandalan (realibility), empathy (empaty) sudah baik bukan berarti diabaikan tetapi Traveloka juga harus mempertahankan dan lebih meningkatkan kualitas pelayanannya. Langkah ini diharapkan dapat lebih meningkatkan kepuasaan pelanggan sehingga menjaga loyalitas pelanggan sendiri di masa yang akan datang.

\subsubsection{Saran kepada Peneliti Selanjutnya}

Dari hasil penelitian koefisien determinasi Kualitas Pelayanan hanya sebesar $47,7 \%$ artinya kualitas pelayanan kurang memberikan kontribusi terhadap loyalitas pelanggan. Peneliti selanjutnya dapat mengembangkan penelitian ini dengan meneliti faktor lain yang dapat mempengaruhi loyalitas pelanggan. Selain itu menggunakan metode lain dalam meneliti loyalitas konsumen, misalnya melalui wawancara mendalam terhadap pelanggan, sehingga informasi yang diperoleh dapat lebih bervariasi daripada angket yang jawabannya telah tersedia. 


\section{DAFTAR PUSTAKA}

“Asosiasi Penyelenggara Jasa Internet Indonesia.” 2018. http://www.apjii.com.

anggan Pada Apotek Dinda Farma Di Klaten Artikel Publikasi Ilmiah.”

“Googletrends.Com.” 2018. http://googletrends.com.

“Id.Techinasia.Com.” 2018. http://www.id.techinasia.com

https://media.neliti.com/media/publications/84504-ID-pengaruh-kualitas-produkdan-kualitas-pe.pdf.

Kusumawati, Andriani. 2011. "Analysing the Influence of Experiential Marketing on Customer Satisfaction and Loyalty." Jurnal Manajemen Pemasaran Modern 3(1): 7586.

“Majalah SWA.” 2018. http://www.swa.co.id.

Mardalis, Ahmad. 2005. "MERAIH LOYALITAS PELANGGAN Ahmad.” 9: 111- 19.

NURAINI, IKKA SEPTYA. 2017. "Faktor-Faktor Yang Mempengaruhi Kepuasan Pelanggan Dan Dampaknya Terhadap Minat Beli Ulang Pada Situs Traveloka.” https://www.noorlib.ir/View/fa/Book/BookView/Image/8089.

“Similiarweb." 2018. http://www.similarweb.com.

Titien Alawiyah. 2011. "Pengaruh Kualitas Pelayanan Terhadap Kepuasan Konsumen Yang Menginap Pada Hotel Diamond Di Kota Samarinda.” 6(2): 803-17.

“Topbrand-Awards.Com.” http://www.topbrand-awards.com.

“Traveloka.Com.” 2018. http://www.traveloka.com.

ZULFIA, YAFIE ERINA. 2016. "Pengaruh Kualitas Pelayanan Terhadap Loyalitas Pelanggan Pada Butik Meliaara Di Bandar Lampug." 